\title{
The use of the Clarus Video System for double-lumen endobronchial tube intubation in a patient with a difficult airway
}

\author{
Young Ri Kim", Byung Hui Jun², and Jie Ae Kim² \\ ${ }^{1}$ Department of Anesthesiology and Pain Medicine, Dongtan Sacred Heart Hospital, Hallym University School of Medicine, Hwasung, \\ ${ }^{2}$ Department of Anesthesiology and Pain Medicine, Samsung Medical Center, Sungkyunkwan University, School of Medicine, Seoul, \\ Korea
}

Recently, video assisted intubation devices have played an important role in difficult airway management. The Clarus Video System (OptiScope ${ }^{\circledR}$, Pacific Medical, Seoul, Korea) is a new video intubating stylet. The use of this airway device has been increasing for difficult airways; however, its use has not been reported for a double lumen endo-bronchial tube (DLT) placement. Here, we describe our experience with the Clarus Video System (CVS) for the placement of a DLT.

A 57 -year-old male patient $(180.7 \mathrm{~cm}, 81.4 \mathrm{~kg})$ with pulmonary metastases from malignant melanoma was admitted to our hospital for pulmonary metastasectomy by video assisted thoracoscopy. Two years ago, he was diagnosed with malignant melanoma of the lip and underwent ENT surgery, an excision of the tumor, and a submandibular lymph node dissection.

After that, he had tomo-therapy (a type of radiation therapy) 5 times and a bronchoscopic biopsy two times with an abnormal position emission tomographic scan.

In the preoperative airway assessment, it appeared that the patient had slightly limited neck motion and shortened hyomental distance. The range of his mouth opening was around two finger widths. After adequate preoxygenation, general anesthesia was induced with thiopental $400 \mathrm{mg}$, sevoflurane and rocuronium $50 \mathrm{mg}$. Mask ventilation was not difficult, and after obtaining an appropriate depth of anesthesia, we tried to intubate the trachea with a 37 Fr left-sided DLT (Bronchocath $^{\circledR}$, Mallinckrodt Medical Ltd, Ireland). At the first attempt, intubation by direct Macintosh laryngscope using a size 3 blade failed; an inability to expose the epiglottis (Cormack- Lehane Grade 4), a limitation in the handling of the laryngoscope due to limited mouth opening, and neck motion were noted. At the third attempt by direct laryngoscope, his trachea was blindly intubated, but we observed that the tracheal balloon of the DLT was torn.

After removal of the DLT, ventilation and oxygenation with a bag and mask continued to be effective, and anesthesia was maintained with a mixture of sevoflurane $5 \%$ and oxygen $100 \%$.

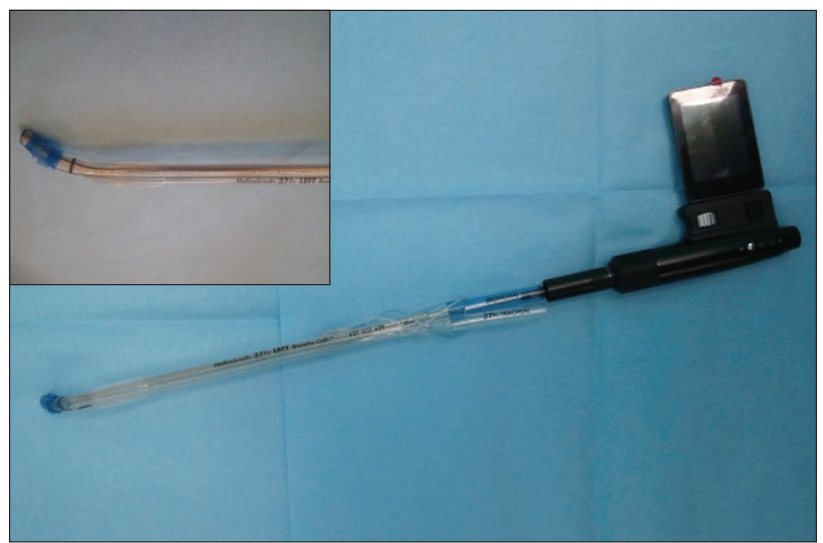

Fig. 1. The Clarus Video System preloaded with a 37 Fr left-sided double lumen tube.

Corresponding author: Jie Ae Kim, M.D., Department of Anesthesiology and Pain Medicine, Samsung Medical Center, 50, Ilwon-dong, Gangnam-gu, Seoul 135-710, Korea. Tel: 82-2-3410-0363, Fax: 82-2-3410-6626, E-mail: jieae.kim@samsung.com

(c) This is an open-access article distributed under the terms of the Creative Commons Attribution Non-Commercial License (http:// creativecommons.org/licenses/by-nc/3.0/), which permits unrestricted non-commercial use, distribution, and reproduction in any medium, provided the original work is properly cited. 
Because of concern for further injury to the soft tissue and unsuccessful intubation, we decided to change the intubation device. The CVS for DLT was lubricated and inserted into the bronchial lumen of a 37 Fr left-sided DLT (Fig. 1). Before the fourth attempt, succinylcholine $100 \mathrm{mg}$ was given because of the amount of time that had passed after the initial bolus use of rocuronium. Tracheal intubation using CVS was tried in a slightly extended neck position while the operator's left thumb elevated the left mandible and tongue. The oro-pharyngeal structures appeared on the monitor attached to the handle and the CVS was advanced along the dorsum of the tongue until the epiglottis, vocal cords, and tracheal rings were seen on the monitor. Then, the operator slid the DLT off the CVS, advanced it into the trachea under direct vision. The intubation was successful upon the first attempt with the use of the CVS and the laryngeal view was Cormack-Lehane grade I on the CVS monitor. The correct position of the DLT was confirmed by auscultation and fiberoptic bronchoscopy. The operation was performed without complications.

DLT has been most widely used in thoracic surgery for lung separation. However, tracheal intubation with DLT is more difficult than a single lumen tracheal tube placement because of its larger outer diameter, longer length, rigid material, and prefixed shape. DLT placement can be especially challenging in a patient with an abnormal airway anatomy or for anticipated difficult tracheal intubations [1]. In our case, the patient had a history of receiving tomotherapy 5 times and oro-pharyngeal surgery; however, we overlooked their significance making a wrong decision about the patient's airway with a quick preoperative airway assessment. Consequently, it resulted in multiple failures and long time trials using a conventional Macintosh laryngoscope.

When DLT placement by direct laryngoscopy is difficult, several alternative techniques are available, such as fiberopticassisted DLT placement or single-lumen ETT and airway exchange catheter technique for replacement with DLT [1]. Cases for diverse modified techniques for DLT placement have been reported [2]. A rigid fiberscope, Bonfils intubation fiberscope, can also be used with DLTs of 37 Fr or larger after appropriate tube shortening [3]. In this case, we used a new video intubating stylet (CVS) designed for DLT for a difficult DLT intubation. The CVS consisted of a rigid intubation stylet, adjustable monitor and rechargeable handle. The distal portion of the CVS can be shaped to adjust for the patient's anatomy. The camera located at the end of the stylet can visualize the laryngeal inlet and vocal cords though the color monitor attached at the handle [4]. It has been already known that CVS facilitates singlelumen endotracheal tube placement in patients with limited neck motion and limited mouth opening [4,5]. The narrowest portion of a 35 Fr DLT has a $5 \mathrm{~mm}$ diameter; thus, an ideal intubating stylet for DLT should have at least $37 \mathrm{~cm}$ in length and be less than $5 \mathrm{~mm}$ in diameter [2]. The CVS designed for DLT has an outer diameter of $5 \mathrm{~mm}$ and is $40.5 \mathrm{~cm}$ in length and could accommodate 35 Fr or larger DLTs.

This case shows that CVS designed for DLT can be used as a useful alternative tool for DLT placement in lung separation patients with difficult airways.

\section{References}

1. Campos JH. Lung isolation techniques for patients with difficult airway. Curr Opin Anaesthesiol 2010; 23: 12-7.

2. O'Connor CJ, O'Connor TA. Use of lighted stylets to facilitate insertion of double-lumen endobronchial tubes in patients with difficult airway anatomy. J Clin Anesth 2006; 18: 616-9.

3. Bein B, Caliebe D, Romer T, Scholz J, Dorges V. Using the Bonfils intubation fiberscope with a double-lumen tracheal tube. Anesthesiology 2005; 102: 1290-1.

4. Cheng WC, Lan CH, Lai HY. The Clarus Video System (Trachway) intubating stylet for awake intubation. Anaesthesia 2011; 66: 1178-80.

5. Kim JK, Kim JA, Kim CS, Ahn HJ, Yang MK, Choi SJ. Comparison of tracheal intubation with the Airway Scope or Clarus Video System in patients with cervical collars. Anaesthesia 2011; 66: 694-8. 